\title{
Carbon Emission Reduction and Coordination Strategies for New Energy Vehicle Closed-Loop Supply Chain under the Carbon Trading Policy
}

\author{
Yan Yin ${ }^{1}{ }^{1}$ and Fengcai Liu $\mathbb{D}^{2}$ \\ ${ }^{1}$ School of Management Science and Engineering, Tianjin University of Finance and Economics, Tianjin 300222, China \\ ${ }^{2}$ College of Management and Economics, Tianjin University, Tianjin 300072, China \\ Correspondence should be addressed to Yan Yin; yinyan@tjufe.edu.cn
}

Received 8 June 2020; Revised 16 May 2021; Accepted 13 July 2021; Published 22 July 2021

Academic Editor: Zhen Zhang

Copyright (c) 2021 Yan Yin and Fengcai Liu. This is an open access article distributed under the Creative Commons Attribution License, which permits unrestricted use, distribution, and reproduction in any medium, provided the original work is properly cited.

\begin{abstract}
Due to the increasingly serious energy crisis and environmental pollution, new energy vehicle (NEV) as a environmentallyfriendly travel tool has been vigorously developed by various countries. However, in 2020, China officially enters the "postsubsidy era" in which the carbon trading scheme will replace the current fiscal and taxation system, affecting the implementation of NEV. Under the carbon trading policy, it has gradually become a major issue how NEV companies achieve production revenue coordination and carbon emission optimization decisions. This study focuses on building a multilevel supply chain for NEV production, sales, and component recycling. In addition, this study establishes a Stackelberg game model dominated by NEV manufacturers and uses contracts to coordinate the model. Results are as follows: (1) With the increasing maturity and perfection of enterprises' carbon emission reduction technology, consumers' demand for new energy vehicles will increase, and the effect will be more obvious when the system centralized decision-making. (2) Since the centralized decision is aimed at the total profit of the system and has the advantage of optimal order quantity, the total benefit of the supply chain is higher than that of the decentralized decision. Moreover, if the cost coefficient of carbon emission reduction is small, the total benefit of the supply chain under the centralized decision will be more obvious. (3) From the perspective of each member of the supply chain, the profit change of the manufacturer is more sensitive to the change of order quantity compared with the cost coefficient of carbon emission reduction. When the cost of carbon emission reduction technology is too high, manufacturers may not have much incentive to carry out technological research and development and innovation, resulting in failure to achieve system optimization. (4) This study designed a revenue-cost-sharing contract coordination mechanism; that is, the retailer will provide part of the revenue to the manufacturer, and the manufacturer will provide recovery compensation to the recycler.
\end{abstract}

\section{Introduction}

In recent years, energy crises and environmental pollution have further intensified and have gradually become the focus of international concern. In this context, new energy vehicles (NEV) have been vigorously promoted by various countries due to their remarkable advantages of low-carbon emissions, environmental protection, and energy saving. Considering the recycling of NEV batteries and components, the closedloop supply chain can minimize resource input as an important means to achieve a circular economy and sustainable development [1], and such supply chains have gradually elicited the attention of many new energy companies and scholars. At present, China's NEV industry remains in the early stages of development. In the past ten years, the Chinese government has vigorously promoted the sustainable development of NEV through a series of policies, such as price regulation and financial subsidies, to mitigate the energy crisis and environmental pollution.

However, the Chinese government decided to gradually cancel the subsidies starting in 2017 to avoid the dependence of the NEV industry on subsidies and reduce the financial 
burden. After the subsidy policy expired in 2020, China will officially enter the "postsubsidy era" and implement a carbon quota trading system to replace the current fiscal subsidy system. The carbon cap refers to the allowable greenhouse gas emission target amount allocated by the government to the enterprise according to regulations. For NEV companies, the carbon cap is the amount of carbon dioxide emission reduction that must be achieved in the production of NEV compared with the production of traditional vehicles. Enterprises producing and selling NEV should try to reduce their carbon emissions. If they do not reach the required emission reduction quotas, then they need to purchase quotas in the NEV market to avoid government fines. If they exceed the initial quota, then they can sell the remaining quota and obtain economic compensation. The subsidy policy compensates for the economic disadvantage of the high production costs of NEV [2]. But when the subsidy policy is canceled, enterprises will face high production costs, which will inevitably affect the production decisions of NEV companies [3].

With the nearing implementation of the carbon quota trading mechanism, some scholars have begun to introduce different contracts into the carbon quota and trading mechanism and discuss the optimization decisions of supply chain member companies, such contracts include costsharing [4] and revenue-sharing [5] contracts. However, research on the closed-loop supply chain of NEV is limited; the focus is only on the secondary supply chain of manufacturers and retailers without considering the importance of recyclers in the closed-loop supply chain of NEV. Furthermore, the actual carbon emission reduction investment cost is remarkable, and the return risk is high because companies need to make major investments in carbon emission reduction technology and equipment.

To supplement the existing research, this article explores the optimization and coordination strategies of a three-level closed-loop supply chain consisting of manufacturers as core companies and retailers and recyclers as member companies under the carbon cap and trading mechanism to solve three main research issues. (1) What is the optimal carbon emission reduction strategy for NEV companies under the carbon cap and trading mechanism? (2) Can the revenuecost-sharing contract coordinate the members of the closedloop supply chain? (3) How does the cost coefficient of carbon emission reduction affect the supply chain benefits and carbon emission reduction effort coefficient?

The remainder of the paper is structured as follows: Section 2 reviews the relevant literature and clarifies the necessity of conducting the research. Section 3 discusses the benefits of the closed-loop supply chain of NEV under centralized and decentralized decisions; Section 4 designs the supply chain coordination mechanism for revenue-costsharing contracts and analyzes the scope of contract parameters. Section 5 presents the numerical analysis. Section 6 concludes the research.

\section{Literature Review}

2.1. Closed-Loop Supply Chain for NEV. Automotive companies, mainly in Japan and the United States, are vigorously developing NEVs. In particular, companies such as Toyota and Tesla have made considerable progress in industrialization. Furthermore, China's automobile production and sales scale have been ranked first globally. Its NEV technology is almost at the same level as those of other countries, specifically in certain areas, although it is inferior to western countries in the traditional automobile field. The sale of a $\mathrm{NEV}$ is the same as that of a traditional vehicle, and this process cannot be separated from the production of parts, product distribution, and sales. Therefore, the supply chain of a NEV is also developed on the basis of the traditional vehicle supply chain. At present, scholars mainly focus on the subsidy policy issues of the NEV supply chain. For example, Zuo et al. [6] established a new government subsidy decision model based on tripartite decision theory in three steps on the premise of minimal government costs and maximum expected revenue to help decision-makers choose the appropriate subsidy target. Gu et al. [7] established an incomplete information game model for a four-tier supply chain, and the subsidies in the supply chain should be allocated to new energy automobile consumers first. Ji et al. [3] used indirect evolution game theory to study the interaction mechanism of complex behaviors between local governments and automakers. Ji also argued that the gradual cancellation of subsidy policies will help the development of the NEV industry. In addition, Xiong and Wang [8] used questionnaires and experiments to analyze the potential consumers' awareness of NEV consumption incentive policies and their sensitivity to purchase intentions; Xiong found that policy awareness and purchase willingness of potential NEV consumers were at a relatively low level.

The recycling of batteries and other components is also an important link in the supply chain of NEVs; thus, scholars have paid increasing attention to closed-loop supply chains that have significant advantages in environmental protection and resource conservation. Modak et al. [9] studied the sustainable recycling process in the production-inventory model of an imperfect production system with a fixed recycling ratio of defective products and believed that the production process using the recycling process had a better effect than the production process without the recycling process. Savaskan and Van Wassenhove [10] found that when manufacturers dominate the supply chain operation, retailers recycling used products is the ideal choice. Furthermore, Huang et al. [11] found that when the recycling competition in the reverse supply chain is not fierce, the dual recycling channel dominates the single recycling channel. By contrast, Yi et al. [12] found that when the retailer dominates the supply chain and awareness of remanufactured products increases, retailers and third parties will have higher return rates for used products. Amrouche and Yan [13] found that 
the retailer-led supply chain system is beneficial to disadvantaged retailers but not to manufacturers. Gu et al. [14] formulated an optimal pricing strategy between the manufacturer and the remanufacturer for the closed-loop supply chain for battery recycling of NEV. Gu found that as the recovery rate increases, the cost of recycling decreases, and the profit increases. Song and Chu [15] discussed the incentive strategy of the battery closed-loop supply chain under different channels and concluded that the total profit increased with the increase of the intensity of the incentive. These studies have discussed the choice of recycling forms and pricing strategies under different leading situations, but most of them have focused on the traditional two-tier supply chain and the choice of leading situations, which did not reflect the characteristics of the three-level closed-loop supply chain of NEVs for parts and battery recycling. Although Xie [16] built a multilevel supply chain network for NEV sales and power battery recycling, research on NEV three-level closed-loop supply chains focusing on the issue of battery recycling models remains at a primary stage.

\subsection{NEV Closed-Loop Supply Chains and Carbon Trading.} To alleviate the energy crisis and improve the environment, China promotes energy vehicles by incentives, such as price regulation and fiscal subsidies. However, as the sales of NEVs continue to increase, the green technology for alternative resources like solar, water, and wind energy, along with efficient equipment and machinery, is costly for setup the manufacturing system [17]. Thus, large-scale fiscal and tax subsidies are difficult to sustain. China's traditional fuel car overcapacity structure has begun to emerge. These problems have prompted China's auto industry to make structural adjustments and begin to implement carbon emission quota restrictions on auto companies. At present, research on carbon trading is comprehensive. Yu et al. [18] solved the pricing problem of distributors under centralized decision-making in consideration of consumers' lowcarbon preferences. Zhang et al. [19] explored how governments and supply chain members can maintain lowcarbon production by supply chain-optimal and government cap decisions. De and Giri [20] used a multiobjective nonlinear mixed-integer programming model to study low-carbon strategies considering transportation costs; Manupati et al. [21] solved the problem of production allocation and inventory in a multilevel supply chain. However, carbon trading issues in the NEV field mainly focus on the promotion of carbon trading policies for NEVs, and few studies focus on low-carbon strategies. For example, the Zero-Emission Vehicles Act implemented in California, USA, has greatly promoted the transformation and upgrading of traditional fuel vehicle companies [22]. Jing [23] studied the relationship between Japanese government policies and the development of NEVs, and the results showed that reasonable government policies can greatly promote the development of NEVs. Zhu et al. [24] analyzed the product difference model of traditional gasoline vehicles and NEVs in the carbon cap and trading supervision system; their results showed that with the increase of carbon quotas for electric vehicles, the market share of electric vehicles and the profits of manufacturers have increased.

\subsection{Closed-Loop Supply Chain Contract for NEVs. Supply} chain members can reduce operating costs by shortening delivery time, setting up cost reduction, implementing optimal scheduling, improving product and service quality and other efforts, but it is not always an economically profitable supply chain [25]. Especially when multiparty companies in the closed-loop supply chain participate in sales and recycling, competition between enterprises and channels will reduce the profit of the supply chain [26], so contract coordination is needed. This reduction is observed for three-tier closed-loop supply chains of NEVs. Cachon [26] pointed out that supply chain coordination aims to attain the consistency of individual behavior under decentralized and centralized decision-making. However, research on coordination mechanisms remains generally focused on traditional supply chains. Zhao et al. [27] proposed that the retailer should share a portion of the revenue with the manufacturer's revenue-sharing and quantity discount contracts. Regarding the manufacturer's sharing of the retailer's cost, Xiao et al. [28] pointed out that when the manufacturer's cost-sharing ratio is small and the wholesale price is moderate, both parties can benefit from this merger contract. Hosseini-Motlagh et al. [4] formulated a cost-sharing contract in a competitive situation because dealers can provide highly qualified services and can meet the needs of more customers. Choi and Guo [29] found that the retailer's risk level under the greedy wholesale price-based revenue-sharing plus marginal payment contract is higher than the zero wholesale pricebased revenue-sharing plus marginal payment contract, so the retailer prefers the latter. Hosseini-Motlagh et al. [30] studied the recycling price with dual functions and found that when manufacturers provide wholesale price discounts to retailers, they can increase the retailer's corporate social responsibility investment.

Besides, considering the greenness of the product and the service conditions of the e-commerce platform, Wu et al. [31] studied a two-level closed-loop supply chain and made the recovery rate and corporate social responsibility investment equal to the centralized retail price by bargaining. The recovery rate and corporate social responsibility investment can effectively coordinate channel conflicts. These studies have shown that using contracts to coordinate closed-loop supply chains is effective. Specifically, for different contract models, Mitra and Webster [32] studied the effect of different recycling legislation on the interests of members when new products competed with remanufactured products. They found that the effect of sharing subsidies was better. On the basis of these findings, Xie et al. [5] combined the revenue-sharing contract of the forward channel with the channel investment cost-sharing contract. They attempted to alleviate the poor recycling issues caused by information asymmetry in recycling channels by hierarchical collection. 
Other scholars have studied the contract under the closed-loop supply chain. For example, considering the issues of corporate social responsibility and equity, Wang et al. [33] believed that the increase in the consumers' awareness of low-carbon environmental protections is seen to increase the substantiality of the contract negotiation space and the feasibility of the coordination mechanism of the 'Altruistic Preference Joint Commission' contract as well in the closedloop supply chain composed of remanufacturer and electronic platform. Xie et al. [25] discussed the contract coordination of the online and offline dual-channel closedloop supply chain and formulates a revenue-sharing mechanism in consideration of the relationship between the recovery rate and the recovery revenue-sharing ratio. After comparing centralized decision-making with manufacturing-led decentralized decision-making, it is concluded that the optimized online and offline prices will increase with the increase in advertising investment.

However, for such high-tech enterprises as the production of new energy vehicles, the key is to maintain the continuity of scientific and technological innovation and other activities in order to realize the transformation and upgrading in the real sense. But Tang et al. [34] believe that China has made great progress in the research and development of new energy vehicles, but the bottleneck of core technology is prominent and the overall research and development level is not high. Especially the lack of core technology represented by electronic control systems restricts the development of the industry. "Subsidized" industrial policies, such as tax reduction and exemption and government subsidies, have promoted the first-mover advantage and scale advantage of China's new energy automobile industry in a short period of time, but still fail to form core technology breakthrough and brand advantage [35] and may even induce some new energy automobile enterprises to "seek compensation" behavior [36]. One of the important reasons is that new energy vehicle enterprises rely excessively on government subsidies, which leads to insufficient motivation and pressure for technology research and development [37]. At the same time, in view of the current technical limitations, new energy vehicles have problems such as insufficient range and unreasonable design of quick charging stations. So, the intention of consumers to buy new energy vehicles, in reality, has not been transformed into actual purchase behavior. The implementation of the carbon trading policy represents that the cultivation policy of the $\mathrm{NEV}$ industry has shifted from the "subsidy" incentive mechanism to the integration of "environmental regulation" and "innovation incentive." One of its important goals is to promote the transformation of NEV enterprises from "relying on subsidies" to obtain short-term profits to "relying on technology" to obtain core competitiveness [38] because the growth of enterprises' core competitiveness and business performance must be supported by the characteristics of R\&D investment and the inherent driving forces reflected therefrom [39]. Only by expanding the scale of R\&D investment and technological innovation can new energy vehicle enterprises limit their carbon emissions within the carbon quota and then make use of the surplus carbon quota to obtain profits and promote the optimization of product structure and the upgrading of the automobile industry. In fact, because the NEV industry is still in its infancy, technical problems are still the main problem at present, which is also the focus of this paper. Therefore, this paper considers the investment degree of new energy vehicle enterprises in carbon emission reduction technology. Other differences are not relevant to the research focus of this paper and therefore are not within the scope of this paper. Analyzing other differences may be a direction for further research.

Setting the retirement age of passenger car batteries as 7 years and commercial vehicle batteries as 5 years, it is predicted that the amount of new energy vehicle batteries will be about $11.6 \mathrm{GWh}$ in 2020 and about $52.8 \mathrm{GWh}$ in 2025. Although some studies have pointed out that thirdparty recycling enterprises in the closed-loop supply chain are detrimental to corporate profits [40], there are differences between the recycling of new energy vehicles and the recycling of general products. Olivo et al. [41] estimated the environmental damage caused by unrecycled packaging waste in Mato Grosso do Sul between 2010 and 2017, of which plastic, glass, steel, and aluminum alone caused a loss of US $\$ 123,820,559.058$. It can be seen that the recovery and disassembly of waste power batteries are of high technical difficulty, and if not properly disposed, it may cause great harm to the environment and require a high cost of environmental remediation. Third-party recycling enterprises can master professional battery raw material recycling technology. At present, some relatively independent thirdparty recycling enterprises have been growing and become important participants in the field of power battery recycling. Therefore, this paper does not consider their own recycling and reuse in the model.

In conclusion, scholars research on closed-loop supply chain mainly concentrated in the closed-loop supply chain of recycling channels to determine the parameters, such as reduced price, making and the degree of government subsidies to discuss, but about the new energy automobile closed-loop supply chain of the manufacture of the new energy vehicles and parts recycling for enterprise technology compared to the general of the closed-loop supply chain is more important. At present, there are few papers considering the efforts of new energy vehicle manufacturers on carbon emission reduction technology. Research on NEVs, closed-loop supply chains, carbon trading, and coordination mechanisms need to be further explored. Moreover, no consideration has been given to the recycling model of three-level closed-loop supply chains for NEVs in the context of carbon trading, corporate emission reduction strategies, and contract coordination. Therefore, given these problems, this study summarizes the supply chain system of NEVs into a three-level closed-loop supply chain composed of manufacturers, retailers, and recyclers. This study discusses the optimal carbon reduction strategy in the sales and recycling process under decentralized and centralized decisions. We designed the revenue-costsharing contract to discuss whether the contract can realize supply chain coordination, aiming at the problem of the inability to coordinate under the decentralized decision of a complex three-level closed-loop supply chain. 


\section{Centralized and Decentralized Decision of NEV Closed-Loop Supply Chains}

3.1. Model Construction and Description. The study considers the three-tier supply chain of manufacturer-retailerrecycler and divides it into forward and reverse logistics stages (Figure 1).

In the forward logistics stage, the manufacturer requires a unit cost $C_{m}$ to produce a new product and sells it to the retailer at the unit wholesale price $W$. Assuming that market demand is $Q$, the retailer sells the new product to the consumer at the unit sales price $P$. In accordance with the carbon trading policy, the government stipulates carbon emissions to be $E$ according to the production of new energy automobile enterprises and $e_{0}$ is the carbon emissions per unit product before low-carbon technology investment. Furthermore, if an enterprise sells a NEV, then the government subsidizes $e$ carbon quotas, and the economic benefit corresponding to each carbon emission is $d$. The company invests a certain amount of carbon emission reduction technology for the production of NEVs. The carbon emission reduction effort coefficient is set as $\tau$; thus, the carbon emission reduction input cost can be expressed as $C(\tau)=(\beta / 2) \tau^{2}(\beta$ is the carbon reduction cost coefficient $)$.

During the reverse logistics phase, third-party recyclers are responsible for the recycling of automotive parts and components throughout the closed-loop supply chain. The recycler collects used parts from the consumer at the unit recovery price $A$ and provides them to the manufacturer at the internal recycling price $b$. The manufacturer produces unit remanufactured products at a cost $C_{r}\left(C_{m}-C_{r}=\delta\right.$ and $\delta>0$ ). Of the total product sales, the proportion of products in which recyclers collected used cars from consumers and used in the manufacturer's remanufacturing process is called the recovery rate $\gamma$. Hence, the recycling effort cost for recyclers to promote the recycling of used parts can be expressed as $C(\gamma)=C_{L} \gamma^{2}$, which means that the recycling effort cost of the recycler is a convex function of the recycling rate $\left(C_{L}\right.$ is the cost coefficient of recycling effort). As the recovery level increases, the cost of recovery efforts will increase significantly, indicating the uneconomical effect of the excessive pursuit of recovery.

The model assumptions are as follows:

(1) The entire closed-loop supply chain system is composed of a manufacturer, a retailer, and a thirdparty recycler. The three are completely rational and perform their duties. The manufacturer produces new products and reproduces waste products, the retailer is responsible for the product sales, and the recycler recycles waste products.

(2) The manufacturer in the system is the dominant player, playing games with retailers and recyclers, and no relationship exists between retailers and recyclers.

(3) Waste car parts collected by recyclers can be reprocessed, and the parts can all be used for reproduction by the manufacturer.

(4) The production process of remanufactured products is the same as that of new products and no differences occur in all aspects of the product; these characteristics are acceptable to consumers.

(5) The information of the entire closed-loop supply chain system is transparent, and the information of manufacturers, retailers, and recyclers is completely symmetrical.

(6) Considering consumers' low-carbon preference, we assume that the inverse demand function of lowcarbon products is $P=\Phi-a Q+h \tau$, where $\Phi>0$ represents the basic price of the product, $a>0$ represents the product sensitivity coefficient of demand for price, and $h>0$ indicates the consumers' preference coefficient for emission reduction.

3.2. Basic Revenue Function. From the above model assumptions and symbol descriptions, the members and the overall return function in the closed-loop supply chain system are expressed as follows:

(1) Manufacturer revenue function:

$$
\Pi_{m}=\left(W-C_{m}\right) Q+(\delta-b) \gamma Q-\frac{\beta}{2} \tau^{2}+\left[E-(1-\gamma+\lambda \gamma-\tau) e_{0} Q+e Q\right] d .
$$

(2) Retailer revenue function:

$$
\pi_{r}=(\Phi+h \tau-W) Q-a Q^{2} .
$$

(3) Recycler revenue function:

$$
\pi_{\mathrm{re}}=(b-A) \gamma Q-C_{L} \gamma^{2} .
$$

(4) Overall return function of the closed-loop supply chain:

$$
\pi=\left(\Phi+h \tau-C_{m}+e d\right) Q+(\delta-A) \gamma Q-a Q^{2}-\frac{\beta}{2} \tau^{2}+E d-C_{L} \gamma^{2}-(1-\gamma+\lambda \gamma-\tau) e_{0} Q d
$$




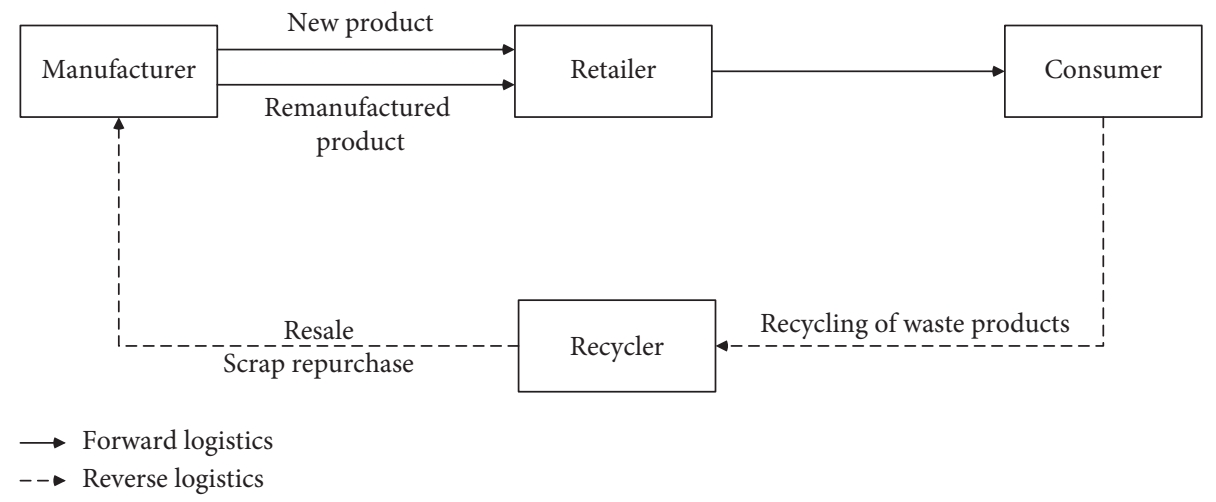

Figure 1: Operation mode of the closed-loop supply chain for NEVs.

\subsection{Centralized and Decentralized Decision Analysis of Closed-Loop Supply Chain System}

\subsubsection{Centralized Decision Analysis of Closed-Loop Supply} Chain System. When the closed-loop supply chain system makes centralized decisions, the common goal of a member within the system is to maximize the overall benefit of the system, which is $\operatorname{MAX}(\pi)$. According to the marginal theory of economics, given that the second-order condition of formula (4) $\left(\partial^{2} \pi / \partial Q^{2}\right)<0,\left(\partial^{2} \pi / \partial \tau^{2}\right)<0$, and $\left(\partial^{2} \pi / \partial \gamma^{2}\right)<0$, according to the first- and second-order conditions, the optimal product supply is as follows:

$$
Q_{1}^{*}=\frac{D}{2 a-B-C} \text {. }
$$

At this time, the optimal carbon emission reduction rate is as follows:

$$
\tau_{1}^{*}=\sqrt{\frac{B}{\beta}} \frac{D}{2 a-B-C} .
$$

The optimal recovery rate is as follows:

$$
\gamma_{1}^{*}=\frac{(\delta-A) C+(1-\lambda) d C}{2 C_{L}(2 a-B-C)} .
$$

The internal recycling price of used parts is as follows:

$$
b_{1}^{*}=\delta .
$$

Among them, $B=\left(\left(h+e_{0} d\right)^{2} / \beta\right), C=([\delta-A+(1$ $\left.\left.-\lambda) e_{0} d\right]^{2} / 2 C_{L}\right)$, and $D=\Phi+\left(e+e_{0}\right) d-C_{m}$.

Therefore, the manufacturer, retailer, and recycler's revenues are recorded as $\pi_{m}\left(\tau_{1}^{*}, Q_{1}^{*}\right), \pi_{r}\left(\tau_{1}^{*}, Q_{1}^{*}\right)$, and $\pi_{\mathrm{re}}\left(\gamma_{1}^{*}, Q_{1}^{*}\right)$, respectively. The total revenue of the NEV closed-loop supply chain is recorded as follows:

$$
\pi\left(\tau_{1}^{*}, Q_{1}^{*}, \gamma_{1}^{*}\right)=\pi_{m}\left(\tau_{1}^{*}, Q_{1}^{*}\right)+\pi_{r}\left(\tau_{1}^{*}, Q_{1}^{*}\right)+\pi_{\mathrm{re}}\left(\gamma_{1}^{*}, Q_{1}^{*}\right) .
$$

\subsubsection{Decentralized Decision Analysis of Closed-Loop Supply} Chain System. In the actual situation, manufacturers, retailers, and recyclers are often relatively independent individuals; thus, unified decision-making and deployment of the three parties are difficult to achieve. When making decisions, each party generally aims to maximize its own interests. Under decentralized decision-making, the manufacturer, as the leader of the Stackelberg game, has a strong ability to control the channel. The manufacturer will first determine the product's carbon emission reduction rate $\tau$. Then, according to the carbon emission reduction rate $\tau$, the manufacturer determines the unit wholesale price $W$ of new products and the internal repurchase price of used products $b$ for maximizing their own interests. Finally, according to the repurchase price $b$ determined by the manufacturer, the recycler determines the recycling rate of used parts $\gamma$, and the retailer determines the new product order quantity $Q$ based on the new product wholesale price $W$ provided by the manufacturer.

According to marginal theory, the reverse induction method is used. Since the second-order condition of formulas (2) and (3) $\left(\partial^{2} \pi_{\mathrm{re}} / \partial \gamma^{2}\right)<0,\left(\partial^{2} \pi_{r} / \partial Q^{2}\right)<0$, therefore, there is a maximum value for the recycler's revenue $\pi_{\mathrm{re}}$ and the retailer's revenue $\pi_{r}$. According to the first-order conditions, the optimal order quantity of retailers and the optimal recovery rate of recyclers are as follows:

$$
\begin{aligned}
Q_{2}^{*} & =\frac{2 a C_{L} e_{0} d(h+1)(\Phi-M)+\left(2 \Phi a C_{L}-M\right) Z}{2 a Z\left(2 a C_{L}+U\right)}, \\
\gamma_{2}^{*} & =\frac{2 a C_{L} e_{0} d(h+1)(\Phi-M)(b-A)+\left(2 \Phi a C_{L}-M\right)(b-A) Z}{4 a C_{L} Z\left(2 a C_{L}+U\right)} .
\end{aligned}
$$


Substituting into formula (1) to get the best unit wholesale price of new products and the best internal repurchase price of waste products:

$$
\begin{aligned}
W_{2}^{*} & =\frac{(\Phi-M)\left(h U-2 a C_{L}\right) e_{0} d-(M-\Phi U) Z}{\left(2 a C_{L}+U\right) Z}, \\
b_{2}^{*} & =\frac{A+\delta+\lambda e_{0}-d e_{0}}{2}
\end{aligned}
$$

Among them, $U=2 a C_{L}+(b+\lambda-\delta-1)(b-A)$, $M=4 a C_{L}\left(C_{m}+e_{0} d\right)$.

According to the first-order condition $\left(\partial \pi_{m} / \partial \tau\right)=0$, the optimal carbon emission reduction rate of the manufacturer can be obtained:

$$
\tau_{2}^{*}=\frac{(\Phi-M) e_{0} d}{Z}
$$

Among them, $Z=\beta\left(4 a C_{L}+U\right)-2 a C_{L} e_{0} d(h+1)$.

Therefore, the manufacturer's revenue is recorded as $\pi_{m}\left(\tau_{2}^{*}, Q_{2}^{*}\right)$, the retailer's revenue is recorded as $\pi_{r}\left(\tau_{2}^{*}, Q_{2}^{*}\right)$, and the recycler's revenue is recorded as $\pi_{\text {re }}\left(\gamma_{2}^{*}, Q_{2}^{*}\right)$. The total revenue of the new energy vehicle closed-loop supply chain is recorded as follows:

$$
\pi\left(\tau_{2}^{*}, Q_{2}^{*}, \gamma_{2}^{*}\right)=\pi_{m}\left(\tau_{2}^{*}, Q_{2}^{*}\right)+\pi_{r}\left(\tau_{2}^{*}, Q_{2}^{*}\right)+\pi_{\text {re }}\left(\gamma_{2}^{*}, Q_{2}^{*}\right)
$$

\section{Closed-Loop Supply Chain Coordination Mechanism Based on Revenue-Cost-Sharing Contract under Decentralized Decision}

Given our use of the standard Stackelberg model, the shift in order quantity and emission reduction coefficients under decentralized decision-making and the centralized decisionmaking will inevitably lead to an increase in supply chain costs, thereby reducing the efficiency of the supply chain. When centralized and decentralized decision-making reach the maximum return, respectively, $P_{1}^{*}<P_{2}^{*}, \quad \gamma_{1}^{*}>\gamma_{2}^{*}$, $Q_{1}^{*}>Q_{2}^{*}$, and $\pi_{1}^{*}>\pi_{2}^{*}$ arises. This result shows that compared with decentralized decision-making, the retailer's product price is lower under centralized decision-making, but the product order quantity, recovery rate of used parts, and overall profit of the supply chain system are higher (this conclusion is further demonstrated in Figure 2). The main reason for this phenomenon is that when the product sales price decreases, consumer demand increases. When consumers find that providing used car parts to recyclers is profitable, the recovery rate will increase, accelerating consumers' replacement of NEVs and further increasing consumer demand for them. Therefore, the closed-loop supply chain can achieve a win-win situation for the entire system and consumers under centralized decision-making.

However, owing to the "double marginal effect" under decentralized decision-making, the supply chain cannot achieve these win-win results, and the maximum benefits of its own entire system members are affected. Therefore, this study introduces the revenue-cost-sharing contract to coordinate the relationships and strategies among members in the closed-loop supply chain system under decentralized decision-making to achieve the goals of the closed-loop supply chain system as a whole.

In the revenue-cost-sharing contract, manufacturers and retailers share the revenue of NEV sales, whereas manufacturers and recyclers share the recycling costs. Among them, the retailer provides the manufacturer with a $1-\phi$ ratio of revenue; the manufacturer provides the recycler with a $1-\varnothing$ ratio of recycling compensation. At this time, the revenue functions of manufacturers, recyclers, and retailers are changed as follows:

(1) Manufacturer's revenue function:

$$
\begin{aligned}
\pi_{m}= & {\left[(\Phi+h \tau)(1-\varphi)+W-C_{m}+e d\right] Q+[\delta-b+(1-\phi) A] \gamma Q-\frac{\beta}{2} \tau^{2} } \\
& +[E-(1-\gamma+\lambda \gamma-\tau) Q] d-(1-\phi) C_{L} \gamma^{2}+a(1-\varphi) Q^{2}
\end{aligned}
$$

(2) Retailer's revenue function:

$$
\pi_{r}=[(\Phi+h \tau) \varphi-W] Q-a \varphi Q^{2} .
$$

(3) Recycler's revenue function:

$$
\pi_{\mathrm{re}}=(b-\phi A) \gamma \mathrm{Q}-\phi C_{L} \gamma^{2}
$$

Proposition 1. If the relevant parameters in the revenuecost-sharing contract meet the conditions of $W=\varphi((\Phi$ $+h \tau)(2 a-B-C)+2 a c / 2 a-B-C), b=\phi \delta$, then the closedloop supply chain system adopts revenue-cost-sharing contract. The coordination status of members in the system is realized under a decentralized decision.

Proof is as follows.

When the contract can be used to make the optimal product supply of the retailer and the recovery rate of the used parts of the recycler in the closed-loop supply chain system under decentralized decision-making reach the corresponding values under centralized decision-making, the system reaches a coordinated state.

Given that $\left(\partial^{2} \pi_{r} / \partial Q^{2}\right)<0, \pi_{r}$ is a strictly concave function about $Q$, and the only point about the maximum value of $Q$ exists. We let $\left(\partial \pi_{r} / \partial Q\right)=0$ to obtain $Q=(\varphi(\Phi+h \tau)$ 


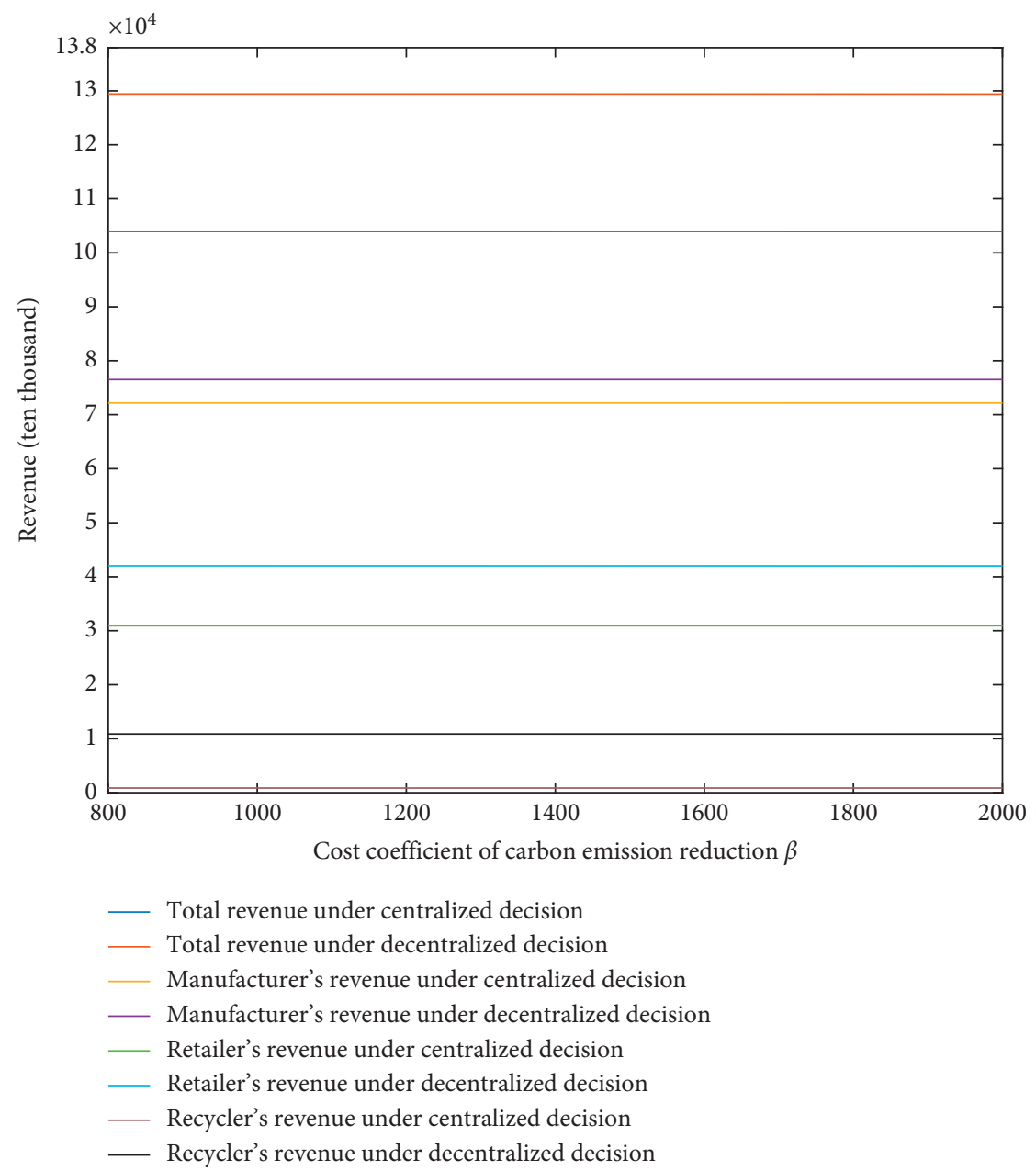

FIGURE 2: Effect of changes in the cost coefficient $\beta$ of supplier carbon emission reduction on the total revenue of the supply chain under different decision-making conditions.

$-W / 2 a \varphi)$. We let this formula be equal to the optimal product supply under centralized decision making. Thus, we can obtain $W^{*}=\varphi((\Phi+h \tau)(2 a-B-C)+2 a c / 2 a-B-C)$. Therefore, when $W=\varphi((\Phi+h \tau)(2 a-B-C)+2 a c / 2 a-B-C)$, the retailer's optimal decision value for NEV supply $Q$ must be the corresponding value under a centralized decision $Q_{1}^{*}$. Considering that $\left(\partial^{2} \pi_{m} / \partial \tau^{2}\right)<0, \pi_{m}$ is a strictly concave function about $\tau$, and the only point about the maximum value of $\tau$ exists. Letting $\left(\partial \pi_{m} / \partial \tau\right)=0$, thus, we obtain $\tau=(\varphi d(\Phi+$ $h \tau)-W d / 2 a \varphi \beta)$. Substituting $W$ in this equation results in $\tau^{*}=((2 a-B-C)(1-d) \Phi-2 a C d / 2 a \beta(2 a-B-C))$.

When the retailer takes the product supply as the optimal value $Q_{1}^{*}$, the recycler's return function is $\pi=(b-\phi$ A) $\gamma Q_{1}^{*}-\phi C_{L} \gamma^{2}$. Given that $\left(\partial^{2} \pi_{\mathrm{re}} / \partial \gamma^{2}\right)<0, \pi_{r e}$ is a strictly concave function about $\gamma$, a maximum point about $\gamma$ exists, and the constraint of $0 \leq \gamma \leq 1$ is achieved. By introducing the generalized Lagrangian multiplier $\eta_{0}$ and setting the $K-T$ point to $\gamma$, the $K-T$ condition can be obtained as follows:

$$
\left\{\begin{array}{l}
(b-\phi A) Q_{1}^{*}-2 \phi C_{L} \gamma-\eta_{0}=0, \\
\eta_{0}(\gamma-1)=0 \\
\eta_{0} \geq 0, \quad 1 \geq \gamma \geq 0 .
\end{array}\right.
$$

It can be known from the $K-T$ condition solution that when $b^{*}=\varphi \delta$, the optimal decision value of the recycler about the recycling rate $\gamma$ of the used parts must be the corresponding value $\gamma^{*}$ under the centralized decision.

According to Proposition 1, under the condition that the ratio of revenue- and cost-sharing meets certain conditions, the revenue-cost-sharing contract can realize the coordination of the supply chain. In addition, the profits of all parties after coordination are higher than those under decentralized decision-making without contract coordination. The effectiveness of this coordination mechanism is further verified by numerical analysis.

\section{Numerical Analysis}

To further understand the effectiveness of corporate emission reductions under centralized decision-making and to demonstrate the coordinating role of revenue- and costsharing contracts, we take the NEV industry as an example to investigate by numerical analysis.

We let $a=10, C_{L}=40,000, C_{m}=3,000, d=40$, $\beta=800, h=10, A=1,500, \lambda=0.9, \delta=2,000, \Phi=250,000$, 
$E=500, e=4$, and $e_{0}=10$. The above numerical calculations show the following: the optimal retailer order amount is 5,560, the retailer's revenue is 309.152 million, the recycler's optimal recycling rate is $37.9 \%$, the recycler's revenue is $8,573,000$, the manufacturer's optimal carbon reduction effort coefficient is $2.97 \%$, the revenue is 72.181 million, and the total revenue is 10.39544 million. Under the centralized decision, the retailer's optimal order amount is 6,484, the retailer's revenue is 42.037 million, the recycler's optimal recycling rate is $48.3 \%$, the recycler's revenue is 10.864 .7 million, the manufacturer's optimal carbon emission reduction effort coefficient is $57.86 \%$, the manufacturer's revenue is $76,521.4$ million, and the total revenue is $1,294.237$ million. When the revenue-cost-sharing coefficient $\phi$ is between 0.6 and 0.8 , and $\varphi$ is between 0.2 and 0.5 , the revenue-cost-sharing contract can realize supply chain coordination. In the case of centralized decision-making, manufacturers' carbon reduction efforts have higher coefficients, retailers have more orders, recyclers have higher recycling rates, and the overall supply chain has relatively high returns.

Next, the manufacturer's carbon emission reduction cost coefficient $\beta$ was changed to examine the effect on relevant variables such as supply chain revenue and optimal order quantity.

First, we analyze the effect of the manufacturer's carbon reduction cost coefficient $\beta$ on ordering volume under different decision-making conditions. When $\beta$ increases, as the cost incurred at the same carbon emission reduction level increases, the benefits decrease. Figure 3 depicts that the optimal ordering amount in the case of centralized decisionmaking must be greater than the ordering amount of decentralized decision-making, specifically when the cost of carbon emission reduction is low. That is, when the $\beta$ coefficient is low, the optimal ordering amount in centralized decision-making must be larger than the order quantity of decentralized decision-making. According to the technology development trend, when the carbon emission reduction cost coefficient is low, it means that the carbon emission reduction technology of the enterprise has been relatively mature and perfect. At this time, consumers are more confident about the performance and safety guarantee of the new energy vehicles produced by the enterprise, which will increase the market demand for new energy vehicles. Egbue and Long [42] found that more consumers would be willing to buy new energy vehicles if technological progress could reduce the cost, increase the mileage, and reduce the charging time. Our research results are consistent with this conclusion.

We further analyze the impact of manufacturers' lowcarbon technologychanges on the total revenue of the supply chain in the case of decentralized and centralized decisionmaking. Figure 2 shows that the benefits of the supply chain under centralized decision-making are higher than the total benefits of the supply chain under decentralized decisionmaking. In addition, if the carbon emission reduction cost coefficient is small, then the advantages of the total revenue of the supply chain under centralized decision-making are evident. This may be because based on the influence of the manufacturer's carbon emission reduction cost coefficient $\beta$ on the order quantity, when the $\beta$ coefficient is low, the optimal order quantity of centralized decision is greater than that of decentralized decision. At the same time, under the centralized decision, the manufacturer, retailer, and recycler all aim at the total profit of the system, reduce the transaction cost of the system, and make the centralized decision supply chain more efficient with the result of the increase of revenue and the decrease of cost.

To further analyze the impact of carbon emission reduction cost coefficients, order quantity, and supply chain revenue, we use $3 \mathrm{D}$ graphs $4-10$ to analyze the impact of carbon emission reduction cost coefficients and order quantity on supply chain revenue under centralized and decentralized decision-making. The $y$-axis represents the carbon emission reduction coefficient $\beta$, the $x$-axis represents the number of new energy vehicles ordered, the $z$-axis represents the revenue of one party in the supply chain, and the three-dimensional curved surface represents the change in revenue.

It can be seen from Figure 4 that under centralized decision-making, the manufacturer's revenue gradually declines as the order volume increases. At a given level of emission reduction, there is always an optimal order quantity, which can enable the manufacturer to get the most benefit. As the emission reduction level increases, the manufacturer's revenue first rises and then falls, but it is not as obvious as the change in order quantity. This shows that the profit changes of manufacturers are more sensitive to the change of order quantity. Therefore, manufacturers can increase publicity and adopt different marketing schemes to stimulate consumer demand in order to improve the profit of new energy vehicles. However, according to the analysis of the impact of the manufacturer's carbon emission reduction cost coefficient $\beta$ on the order quantity, it can be seen that the premise essence of increasing sales is technological innovation and improvement of technology maturity.

It can be seen from Figures 5 and 6 that under centralized decision-making, the revenue of retailers and recyclers rises with the increase in order volume. When manufacturers' emission reduction levels are increasing, the revenues of retailers and recyclers are slowly increasing, but they do not show the distinctive characteristics of manufacturers' incomes changing with emission reduction levels. This means that when the manufacturer's investment in carbon emission reduction technology costs higher, the manufacturer's profits will be significantly reduced, while the profits of retailers and recyclers will increase accordingly. This may be because although consumer demand for new energy vehicles has increased due to technological updates, the increase in sales cannot make up for the costs that manufacturers have invested in improving the performance of new energy vehicles. However, in the case of high input cost of carbon emission reduction technology, manufacturers may not have much incentive to carry out technology research and development and innovation (which can be confirmed in the analysis of the impact of the change of manufacturer's carbon emission reduction cost level $\beta$ on carbon emission reduction effort coefficient), so that the system may not 


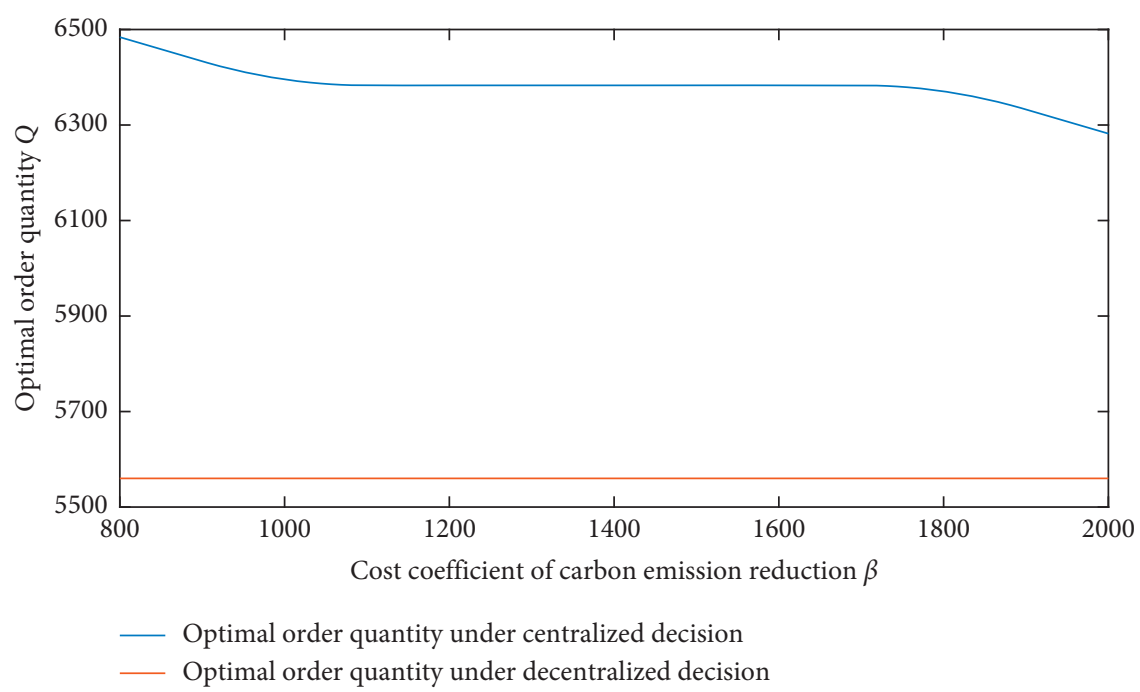

FIGURE 3: Effect of changes in manufacturers' carbon reduction cost coefficient $\beta$ on ordering volume under different decision-making conditions.

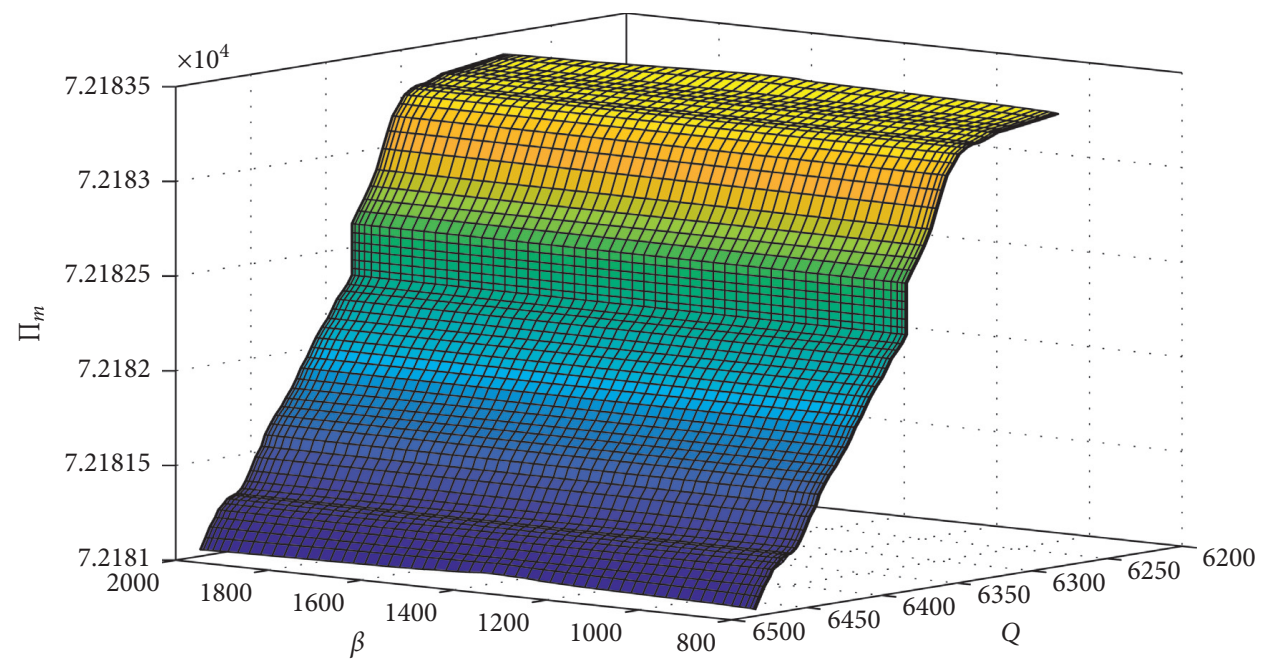

FIGURE 4: The impact of carbon emission reduction cost factors and order quantities on manufacturers' revenues under centralized decisionmaking.

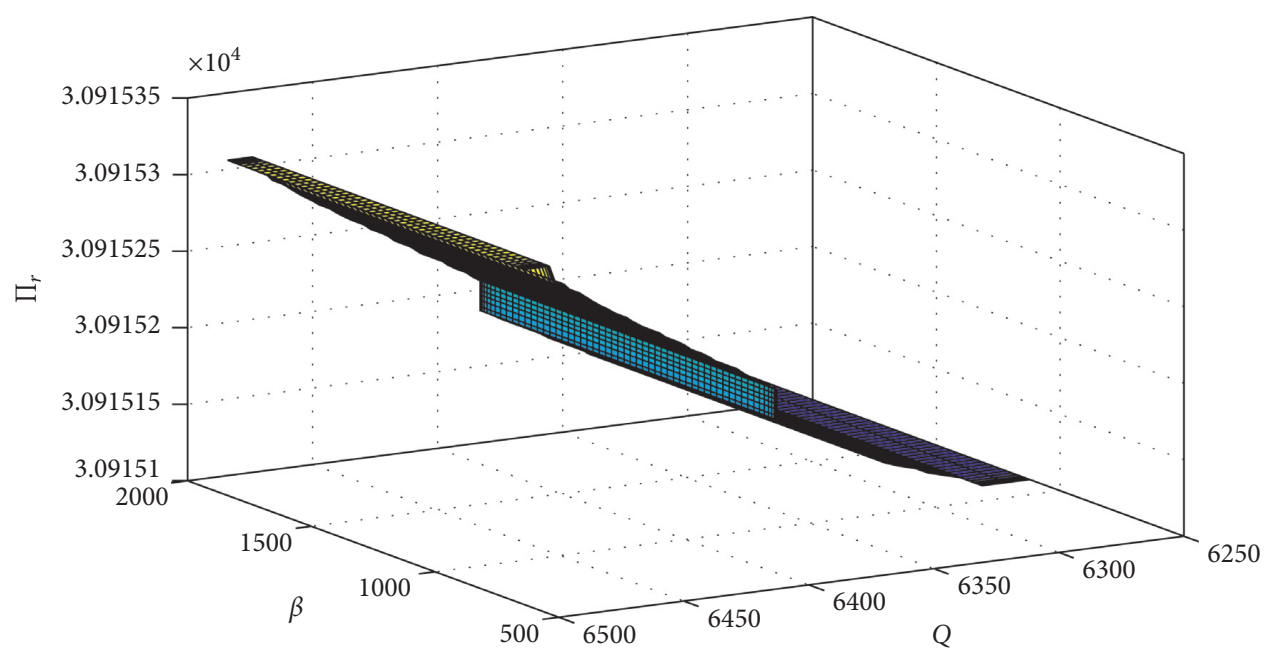

FIGURE 5: The impact of carbon emission reduction cost factors and order quantities on retailer revenue under centralized decision-making. 


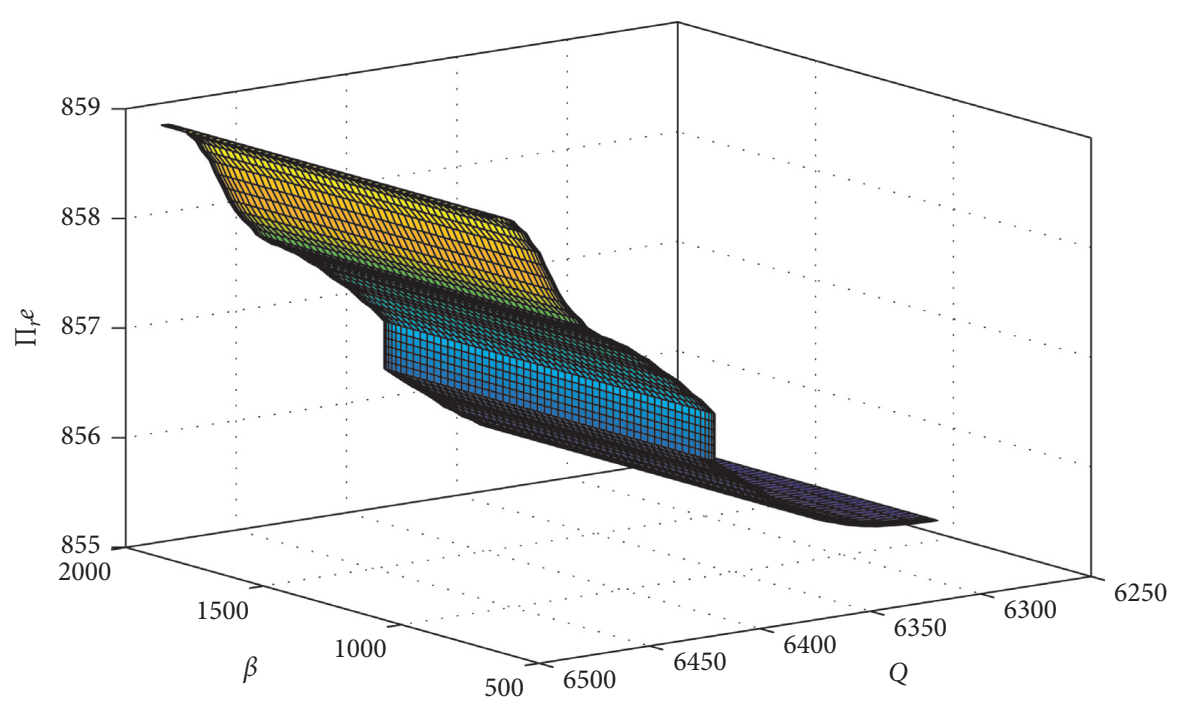

FIGURE 6: The impact of carbon emission reduction cost factors and order quantities on the revenue of recyclers under centralized decisionmaking.

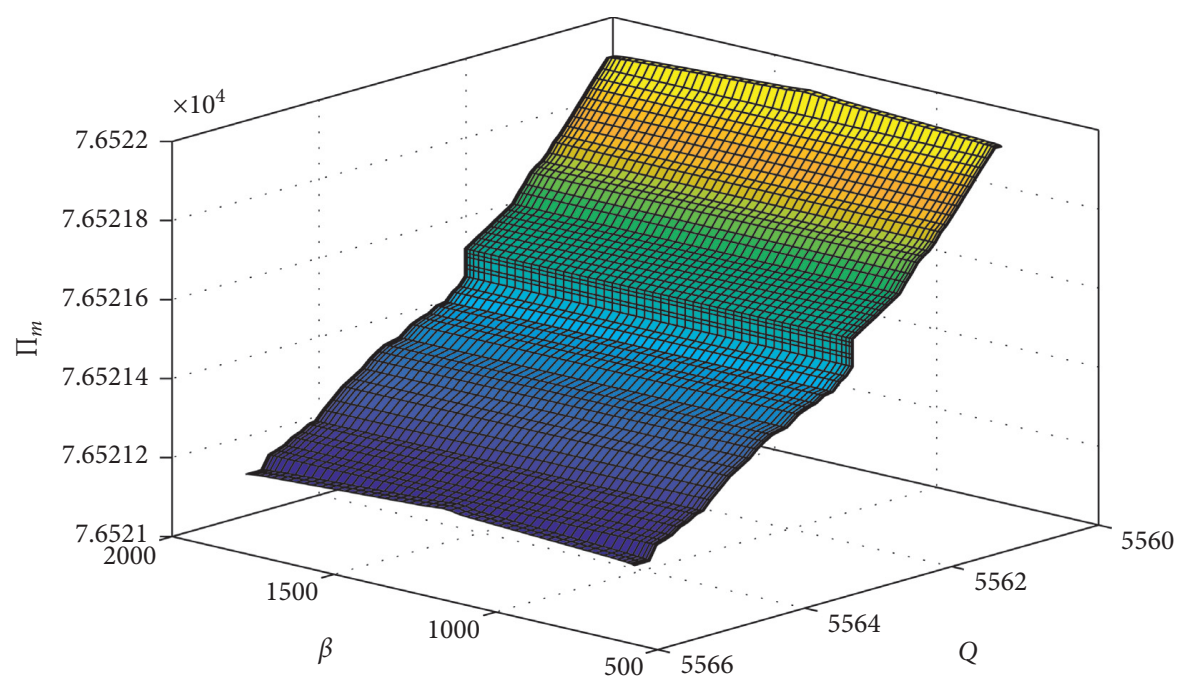

Figure 7: The impact of carbon emission reduction cost factors and order quantities on manufacturers' earnings under decentralized decision.

achieve the optimal result. As can be seen from Figures 7-9, the impact of carbon emission reduction efforts and order quantities on the income of supply chain members under decentralized decision-making is basically the same as that under centralized decision-making, but the benefits that can be obtained by supply chain members under centralized decision-making are higher.

We analyze the effect of changes in manufacturers' carbon reduction technology levels $\beta$ on the carbon reduction effort coefficient under different decision-making situations. Figure 10 shows that the carbon emission reduction effort coefficient under centralized decision-making is greater than that under decentralized decision-making. Therefore, centralized decision-making can improve the total supply chain revenue while promoting environmental protection. But as the cost of carbon emission reductions continues to increase, the carbon emission reduction effort coefficients in centralized and decentralized situations continue to decrease and as the cost reduction coefficient of carbon emissions continues to increase, the emission reduction coefficient under centralized decision-making will continue to decline and gradually move closer to the emission reduction coefficient under decentralized decisionmaking. This indicates that as the cost of carbon emission reduction technology increases and the difficulty increases, the manufacturer is less willing to carry out technological innovation because it will increase his financial risk.

The revenue-cost-sharing ratio satisfies $\phi, \varphi \in[0,1]$ to meet the constraints of the establishment of a revenue-costsharing contract. The carbon emission reduction effort coefficient can be calculated from the proof in Proposition 1 to $56.8 \%$, showing that the carbon reduction effort coefficient of decentralized decision-making under the contract has been greatly improved. The change in $\varphi, \phi$ can be used to 


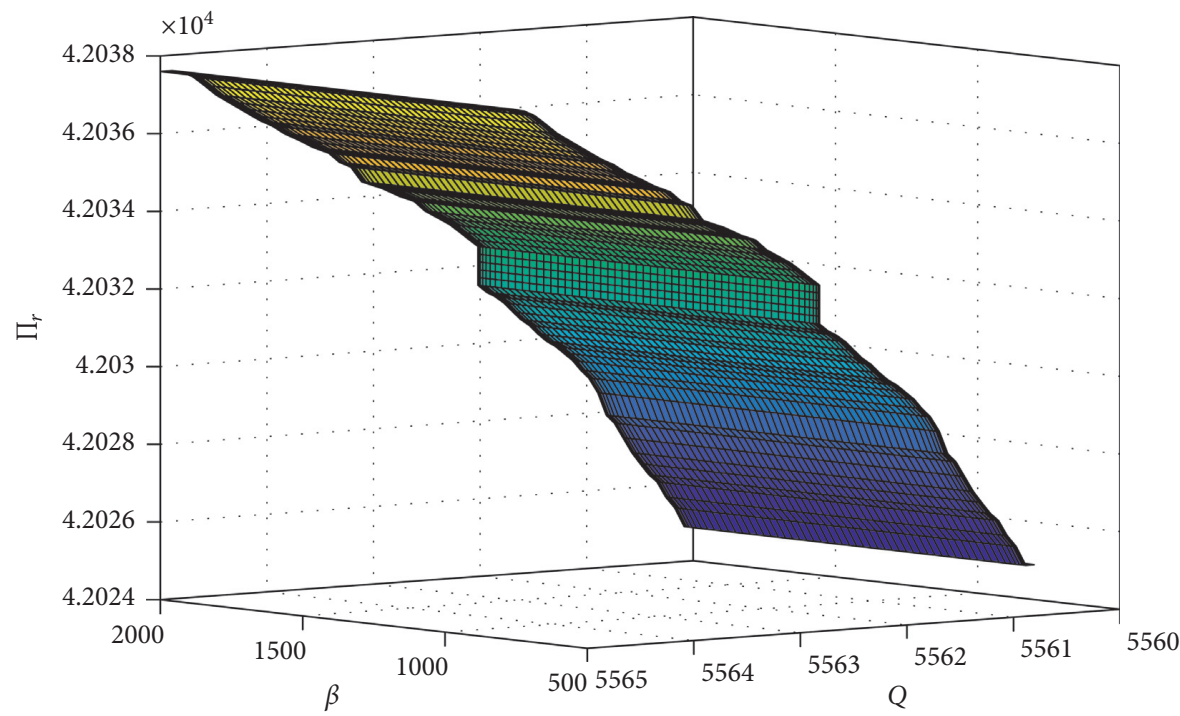

Figure 8: The impact of carbon emission reduction cost factors and order quantities on retailer revenue under decentralized decisionmaking.

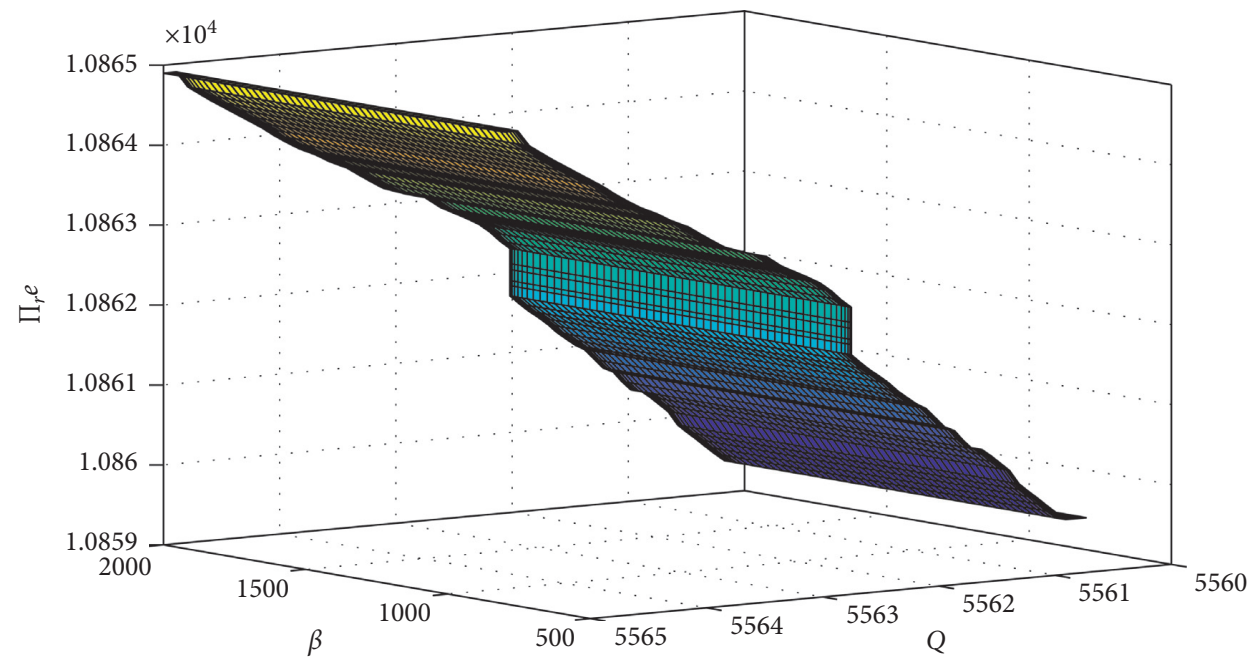

FIGURE 9: The impact of carbon emission reduction cost factors and order quantities on the revenue of recyclers under decentralized decision-making.

obtain the change rule of the three members and the supply chain revenue under different proportions under the noncontract decentralized decision and the revenue-cost-sharing contract decentralized decision; that is, $\pi_{m}, \pi_{r}, \pi_{\mathrm{re}}, \pi$ and $\pi_{m}^{\prime}, \pi_{r}^{\prime}, \pi_{\mathrm{re}}^{\prime}, \pi^{\prime}$.

Table 1 shows that when the revenue-cost-sharing ratio satisfies $\phi \in[0.6,0.8], \varphi \in[0.2,0.4]$, the income of NEV manufacturers, retailers, and recyclers after coordination by the sharing contract is higher than that under the decentralized decision-making situation without contract coordination, and the total revenue of the supply chain is correspondingly improved. This finding shows that when the revenue-cost-sharing contract is used to coordinate the supply chain, the profits of participating companies can be improved to a certain extent. Among the companies, the leading manufacturer can obtain most of the supply chain's profit appreciation, so its profit growth is the largest. Furthermore, the effectiveness of the contract coordination mechanism designed in this study is verified. 


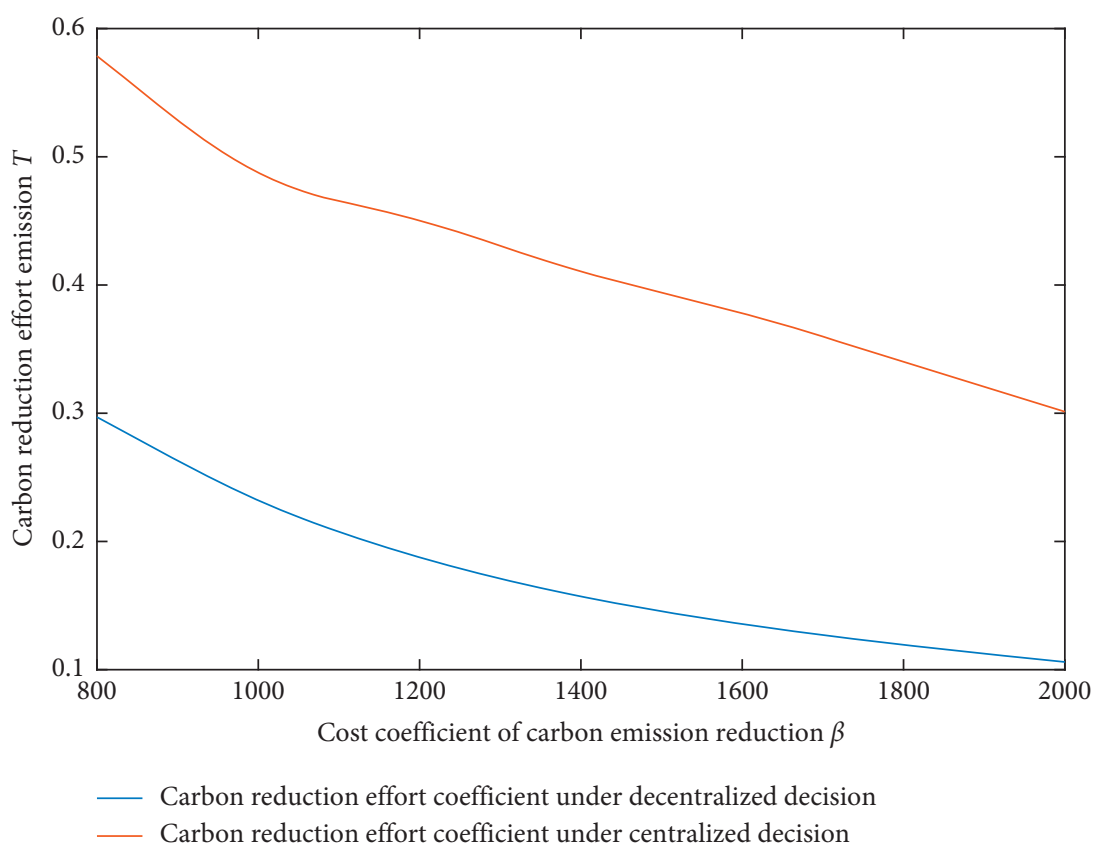

FigURE 10: Effect of changes in supplier carbon emission reduction cost coefficient $\beta$ on emission reduction effort coefficient under different decision-making conditions.

TABLE 1: Changes in profits after coordination.

\begin{tabular}{|c|c|c|c|c|c|c|c|c|}
\hline Proportion of revenue share & $\pi_{m}$ & $\pi_{m}^{\prime}$ & $\pi_{r}$ & $\pi_{r}^{\prime}$ & $\pi_{\mathrm{re}}$ & $\pi_{\mathrm{re}}^{\prime}$ & $\pi$ & $\pi^{\prime}$ \\
\hline $\begin{array}{l}\phi=0.5 \\
\varphi=0.1\end{array}$ & 72181.8 & 87838.4 & 30915.2 & 30630.1 & 857.3 & 736.1 & 103954.4 & 119204.6 \\
\hline $\begin{array}{l}\phi=0.6 \\
\varphi=0.2\end{array}$ & 72181.8 & 84487.4 & 30915.2 & 37260.2 & 857.3 & 883.3 & 103954.4 & 122630.9 \\
\hline $\begin{array}{l}\phi=0.7 \\
\varphi=0.3\end{array}$ & 72181.8 & 80136.4 & 30915.2 & 40890.2 & 857.3 & 1030.5 & 103954.4 & 122057.1 \\
\hline $\begin{array}{l}\phi=0.8 \\
\varphi=0.4\end{array}$ & 72181.8 & 75785.4 & 30915.2 & 43452.3 & 857.3 & 1177.7 & 103954.4 & 120415.4 \\
\hline $\begin{array}{l}\phi=0.9 \\
\varphi=0.5\end{array}$ & 72181.8 & 71434.4 & 30915.2 & 56815.3 & 857.3 & 1324.9 & 103954.4 & 129574.6 \\
\hline
\end{tabular}

\section{Conclusion}

Under the carbon cap and trading mechanism, this study considers a three-tier NEV closed-loop supply chain system composed of manufacturers, retailers, and recyclers. This study discusses the decision-making situations of ordinary decentralized and centralized decision-making. On the basis of this discussion, the "revenue- and expense-sharing" contract design is used to achieve system coordination and analyze the effect of carbon emission reduction cost coefficient on supply chain order quantity, revenue, and carbon emission reduction effort input. This study enriches the research on new energy vehicles by introducing revenuecost-sharing contracts and provides a theoretical basis for the government to encourage new energy vehicle enterprises and guide the active cooperation of the new energy vehicle industry chain.

The research results are as follows:

(1) In the case of centralized decision making, the optimal order quantity is greater than that of decentralized decision making, and when the carbon emission reduction cost coefficient is low, the advantage of centralized decision making is more obvious. That is, with the increasing maturity and perfection of enterprises' carbon emission reduction technology, consumers' demand for new energy vehicles will increase, and the effect will be more obvious when the system centralized decisionmaking.

(2) Since the centralized decision is aimed at the total profit of the system and has the advantage of optimal order quantity, the total benefit of the supply chain is higher than that of the decentralized decision. Moreover, if the cost coefficient of carbon emission reduction is small, the total benefit of the supply chain under the centralized decision will be more obvious.

(3) From the perspective of each member of the supply chain, the profit change of the manufacturer is more sensitive to the change of order quantity compared 
with the cost coefficient of carbon emission reduction. However, according to the first conclusion, the premise of increasing sales volume is technological innovation and improvement of technology maturity. When manufacturers invest in higher carbon emission reduction technology costs, this is more beneficial to the income of retailers and recyclers because there is the optimal order quantity advantage. But the increase in sales volume cannot make up for the cost invested by manufacturers to improve the performance of new energy vehicles. Therefore, when the cost of carbon emission reduction technology is too high, manufacturers may not have much incentive to carry out technological research and development and innovation, resulting in failure to achieve system optimization.

(4) This study designed a revenue-cost-sharing contract coordination mechanism. That is, the retailer will provide part of the revenue to the manufacturer, and the manufacturer will provide recovery compensation to the recycler. When the distribution ratio between manufacturer and retailer, manufacturer and recycler is satisfied, the contract can realize the complete coordination of the supply chain and effectively improve the profit of each enterprise.

This study also provides decision-making guidance for the development of new energy vehicle enterprises under the carbon trading policy. In order to promote the development of new energy vehicles, first of all, the government should encourage enterprises to carry out technological innovation and research and development. The government can provide certain funds to give appropriate support to the implementation of new energy vehicle technology innovation projects and guide enterprises to increase investment in technology development, engineering, standard-setting, market application, and other aspects. The government should continuously expand the benefits of participating in collaborative innovation between new energy vehicle enterprises and universities and establish a technology innovation system combining production, education, and research through the formulation, publication, publicity, typical demonstration, and establishment of innovation strategic alliance of new energy vehicle industry policies. The government should strengthen its guiding role and improve relevant laws and regulations, promoting the development of China's new energy vehicle industry.

In order to increase the sales of new energy vehicles, the government can provide subsidies for the demonstration of new energy vehicles in the field of public service and the pilot project of individual purchases of new energy vehicles. The government should play a leading role in procurement, increase government procurement, give priority to clean energy vehicles in the procurement of government vehicles, and encourage consumers to buy and use new energy vehicles. For retailers, they can expand sales channels, make full use of the advantages of Internet communication to publicize the performance of new energy vehicles, and adopt diversified marketing plans for different customer groups.

Manufacturers' carbon emission reduction technology input and recyclers' cost of recycling new energy vehicle parts and power batteries are the problems that need to be solved to promote the development of new energy vehicles. In addition to the government's financial subsidies and policy support for enterprises, reasonable income distribution between retailers and manufacturers, and appropriate cost-sharing between manufacturers and retailers can make the system achieve the optimal.

However, this study also has some limitations and future research directions. First of all, with people's attention to environmental protection, consumers' green preference for products is gradually increasing, and consumers' green awareness is becoming a key factor that cannot be ignored in determining the success of the sales and recycling process of new energy vehicles. Therefore, it may become the research direction and focus of this study to consider the impact of consumers' green awareness on their purchasing decisions, the profits of manufacturers, retailers, and remanufacturers, and even the profits of the entire closed-loop supply chain. Secondly, there are many uncertainties in the carbon trading market, and the carbon price may be disturbed due to the change of various factors, which will affect the original production plan of the manufacturer and generate additional emergency disposal costs. Therefore, the next step can study the optimal response strategy of the automobile manufacturer when the carbon price is disturbed.

\section{Appendix}

\section{A. Calculation of Centralized Decision-Making}

Under centralized decision-making, the common goal of the members of the system to make decisions is to maximize the benefits of the entire system. Therefore, the first-order conditions of formulas (1)-(3) are as follows:

$$
\begin{aligned}
& \frac{\partial \pi}{\partial Q}=\Phi+h \tau-C_{m}+e d+(\delta-A) \gamma-2 a Q-(1-\gamma+\lambda \gamma-\tau) e_{0} d, \\
& \frac{\partial \pi}{\partial \tau}=h Q-\beta \tau+e_{0} Q d, \\
& \frac{\partial \pi}{\partial \gamma}=(\delta-A) Q-2 C_{L} \gamma+e_{0} Q d-\lambda e_{0} Q d .
\end{aligned}
$$

Since the second-order conditions of formulas (1)-(3) are all less than 0 , that is $\left(\partial^{2} \pi / \partial Q^{2}\right)=-2 a<0,\left(\partial^{2} \pi / \partial \tau^{2}\right)=$ $-\beta<0,\left(\partial^{2} \pi / \partial \gamma^{2}\right)=-2 C_{L}<0$, so let $(\partial \pi / \partial Q)=0,(\partial \pi / \partial \tau)$ $=0,(\partial \pi / \partial \gamma)=0$ as follows: 


$$
\begin{aligned}
Q & =\frac{\Phi+h \tau-C_{m}+e d+(\delta-A) \gamma-(1-\gamma+\lambda \gamma-\tau) e_{0} d}{2 a}, \\
\tau & =\frac{\left(h+e_{0} d\right) Q}{\beta}, \\
\gamma & =\frac{(\delta-A) Q+(1-\lambda) e_{0} Q d}{2 C_{L}} .
\end{aligned}
$$

Substituting the equations of $\tau$ and $\gamma$ into the equation of $Q$ at the same time, when $B=\left(\left(h+e_{0} d\right)^{2} / \beta\right)$, $C=\left(\left[\delta-A+(1-\lambda) e_{0} d\right]^{2} / 2 C_{L}\right), \quad D=\Phi+\left(e+e_{0} d\right)-C_{m}$, we can get the following

$$
\Phi+\left(e+e_{0}\right) d-C_{m}+\frac{\left(h+e_{0} d\right)^{2} Q}{\beta}+\frac{\left[\delta-A+(1-\lambda) e_{0} d\right]^{2} Q}{2 C_{L}}=2 a Q
$$

Therefore, the optimal order quantity under centralized decision is $Q_{1}^{*}=(D / 2 a-B-C)$. Substituting $Q_{1}^{*}$ into the equations of $\tau$ and $\gamma$ can obtain the optimal carbon reduction rate $\tau_{1}^{*}=\sqrt{B / \beta}(D / 2 a-B-C)$, the optimal recovery rate is $\gamma_{1}^{*}=\left((\delta-A) C+(1-\lambda) d C / 2 C_{L}(2 a-B-C)\right)$.

\section{B. Calculation of Decentralized Decision}

First, the optimal decision of the recycler and retailer in the third stage is solved. From the first and second-order conditions of formulas (2) and (3), we can obtain the following:

$$
\begin{aligned}
\frac{\partial \pi_{\mathrm{re}}}{\partial \gamma} & =(b-A)-2 C_{L} \gamma, \\
\frac{\partial^{2} \pi_{\mathrm{re}}}{\partial \gamma^{2}} & =-2 C_{L}<0, \\
\frac{\partial \pi_{r}}{\partial Q} & =\Phi+h \tau-W-2 a Q, \\
\frac{\partial^{2} \pi_{r}}{\partial Q^{2}} & =-2 a<0 .
\end{aligned}
$$

Therefore, the revenue $\pi_{\text {re }}$ of the recycler and the revenue $\pi_{r}$ of the retailer both have maximum values. From the firstorder conditions, the optimal recovery rate of the recycler and the optimal order quantity of the retailer are as follows:

$$
\begin{gathered}
\gamma=\frac{(b-A) Q}{2 C_{L}}, \\
Q=\frac{\Phi+h \tau-W}{2 a} .
\end{gathered}
$$

Substituting formulas (B.2) and (B.3) into formula (1), the wholesale price of the new product unit and the internal repurchase price of the waste product can be obtained from the first-order conditions:

$$
\begin{gathered}
W=\frac{\Phi U+M+\left(h U-2 a C_{L}\right) \tau}{U+2 a C_{L}}, \\
b_{2}^{*}=\frac{A+\delta+\lambda e_{0}-d e_{0}}{2} .
\end{gathered}
$$

Among them, $U=2 a C_{L}+(b+\lambda-\delta-1)(b-A)$, $M=4 a C_{L}\left(C_{m}+e_{0} d\right)$.

Substituting equations (B.4) and (B.5) into equation (1), according to the first-order condition $\left(\partial \pi_{m} / \partial \tau\right)=0$, the optimal carbon emission reduction rate of the manufacturer can be obtained:

$$
\tau_{2}^{*}=\frac{(\Phi-M) e_{0} d}{Z}
$$

Among them, $Z=\beta\left(4 a C_{L}+U\right)-2 a C_{L} e_{0} d(h+1)$.

According to the inverse solution, the formula (B.6) is substituted into the formula (B.4) to obtain the optimal unit wholesale price of the new product:

$$
W_{2}^{*}=\frac{(\Phi-M)\left(h U-2 a C_{L}\right) e_{0} d-(M-\Phi U) Z}{\left(2 a C_{L}+U\right) Z} .
$$

Substituting formulas (B.6) and (B.7) into formulas (B.2) and (B.3), the optimal order quantity of retailers and the optimal recovery rate of recyclers can be obtained as follows:

$$
\begin{aligned}
Q_{2}^{*} & =\frac{2 a C_{L} e_{0} d(h+1)(\Phi-M)+\left(2 \Phi a C_{L}-M\right) Z}{2 a Z\left(2 a C_{L}+U\right)}, \\
\gamma_{2}^{*} & =\frac{2 a C_{L} e_{0} d(h+1)(\Phi-M)(b-A)+\left(2 \Phi a C_{L}-M\right)(b-A) Z}{4 a C_{L} Z\left(2 a C_{L}+U\right)} .
\end{aligned}
$$




\section{Proof of Proposition 4.1}

Since the first and second-order conditions of formula (15) are $\left(\partial \pi_{r} / \partial Q\right)=(\Phi+h \tau) \varphi-2 a \varphi Q-W,\left(\partial^{2} \pi_{r} / \partial Q^{2}\right)=-2 a \varphi$ $<0$. Let $\left(\partial \pi_{r} / \partial Q\right)=0$ get $Q=(\varphi(\Phi+h \tau)-W / 2 a \varphi)$. Let $Q$ be equal to the optimal supply of products under centralized decision-making, that is $(\varphi(\Phi+h \tau)-W / 2 a \varphi)=(D$ $/ 2 a-B-C)$, then $W^{*}=\varphi((\Phi+h \tau) \quad(2 a-B-C)+2 a c$ $/ 2 a-B-C)$.

Since the first and second-order conditions of formula (14) are $\left(\partial \pi_{m} / \partial \tau\right)=-\beta \tau+Q d=0,\left(\partial^{2} \pi_{m} / \partial \tau^{2}\right)=-\beta<0$, let $\left(\partial \pi_{m} / \partial \tau\right)=0$, we get $\tau=(Q d / \beta)=(\varphi d(\Phi+h \tau)$ $-W d / 2 a \varphi \beta)$. Substituting $W$ in the above, we can obtain $\tau^{*}=((2 a-B-C)(1-d) \Phi-2 a C d / 2 a \beta(2 a-B-C))$.

When the retailer's product supply is the optimal value $Q_{1}^{*}$, the revenue function of the recycler can be obtained as $\pi=(b-\phi A) \gamma Q_{1}^{*}-\phi C_{L} \gamma^{2}$. Since the second-order condition of formula (16) is $\left(\partial^{2} \pi_{\mathrm{re}} / \partial \gamma^{2}\right)=-2 \phi C_{L}<0$, and satisfy the constraint condition of $0 \leq \gamma \leq 1$, the generalized Lagrangian multiplier $\eta_{0}$ is introduced, And set the $K-T$ point to $\gamma$, the $K-T$ conditions can be obtained as follows:

$$
\left\{\begin{array}{l}
(b-\phi A) Q_{1}^{*}-2 \phi C_{L} \gamma-\eta_{0}=0 \\
\eta_{0}(\gamma-1)=0 \\
\eta_{0} \geq 0, \quad 1 \geq \gamma \geq 0
\end{array}\right.
$$

The following are solved by the system of equations:

(1) When $C_{L}>((b-\phi A) D / 2 \phi[2(b-\phi A) D+2 a-B])+$ $\left(2\left[\delta-A+\left(1-\lambda e_{0} d\right)\right] / 2(b-\phi A) D+2 a-B\right)$, then $\gamma=\left((b-\phi A) Q_{1}^{*} / 2 \phi C_{L}\right)$;

(2) When $C_{L} \leq((b-\phi A) D / 2 \phi[2(b-\phi A) D+2 a-B])$ $+\left(2\left[\delta-A+\left(1-\lambda e_{0} d\right)\right] \quad / 2(b-\phi A) D+2 a-B\right)$, then $\gamma=1$.

If $b^{*}=\phi \delta$, then

(1) When $C_{L}>((\delta-A) D / 4 \phi(\delta-A) D+2(2 a-B))$ $+\left(2\left[\delta-A+\left(1-\lambda e_{0} d\right)\right] / 2 \phi(\delta-A) D+2 a-B\right)$, then $\gamma=\gamma^{*}$

(2) When $C_{L} \leq((\delta-A) D / 4 \phi(\delta-A) D+2(2 a-B))+$ $\left(2\left[\delta-A+\left(1-\lambda e_{0} d\right)\right] / 2 \phi(\delta-A) D+2 a-B\right)$, then $\gamma=1$.

However, it can be seen from the model that (2) does not meet the basic assumptions and needs to be discarded. Therefore, when $b^{*}=\varphi \delta$, the optimal value of the recycler's decision about the recycling rate of waste parts $\gamma^{*}$ must be the corresponding value under the centralized decision.

\section{Data Availability}

All the shared data are in this manuscript.

\section{Conflicts of Interest}

The authors declare that they have no conflicts of interest.

\section{References}

[1] H. Peng, N. Shen, H. Liao, H. Xue, and Q. Wang, "Uncertainty factors, methods, and solutions of closed-loop supply chain-a review for current situation and future prospects," Journal of Cleaner Production, vol. 254, Article ID 120032, 2020.

[2] X. Zhang and C. Zhang, "Optimal new energy vehicle production strategy considering subsidy and shortage cost," Energy Procedia, vol. 75, pp. 2981-2986, 2015.

[3] S. F. Ji, D. Zhao, and R. J. Luo, "Evolutionary game analysis on local governments and manufacturers' behavioral strategies: impact of phasing out subsidies for new energy vehicles," Energy, vol. 189, Article ID 116064, 2019.

[4] S. M. Hosseini-Motlagh, M. Nouri-Harzvili, M. Johari, and B. R. Sarker, "Coordinating economic incentives, customer service and pricing decisions in a competitive closed-loop supply chain," Journal of Cleaner Production, vol. 255, Article ID 120241, 2020.

[5] J. Xie, W. Zhang, L. Liang, Y. Xia, J. Yin, and G. Yang, "The revenue and cost sharing contract of pricing and servicing policies in a dual-channel closed-loop supply chain," Journal of Cleaner Production, vol. 191, pp. 361-383, 2018.

[6] W. Zuo, Y. Li, and Y. Wang, "Research on the optimization of new energy vehicle industry research and development subsidy about generic technology based on the three-way decisions," Journal of Cleaner Production, vol. 212, pp. 46-55, 2019.

[7] X. Gu, P. Ieromonachou, and L. Zhou, "Subsidising an electric vehicle supply chain with imperfect information," International Journal of Production Economics, vol. 211, pp. 82-97, 2019.

[8] Y. Xiong and L. Wang, "Policy cognition of potential consumers of new energy vehicles and its sensitivity to purchase willingness," Journal of Cleaner Production, vol. 261, Article ID 121032, 2020.

[9] N. M. Modak, N. Modak, S. Panda et al., "Analyzing structure of two-echelon closed-loop supply chain for pricing, quality and recycling management," Journal of Cleaner Production, vol. 171, pp. 512-528, 2018.

[10] R. C. Savaskan and L. N. Van Wassenhove, "Reverse channel design: the case of competing retailers," Management Science, vol. 52, no. 1, pp. 1-14, 2006.

[11] M. Huang, M. Song, L. H. Lee, and W. K. Ching, "Analysis for strategy of closed-loop supply chain with dual recycling channel," International Journal of Production Economics, vol. 144, no. 2, pp. 510-520, 2013.

[12] P. Yi, M. Huang, L. Guo, and T. Shi, "Dual recycling channel decision in retailer oriented closed-loop supply chain for construction machinery remanufacturing," Journal of Cleaner Production, vol. 137, pp. 1393-1405, 2016.

[13] N. Amrouche and R. Yan, "Can a weak retailer benefit from manufacturer-dominant retailer alliance?" Journal of Retailing and Consumer Services, vol. 20, no. 1, pp. 34-42, 2013.

[14] X. Gu, P. Ieromonachou, L. Zhou, and M. L. Tseng, "Developing pricing strategy to optimise total profits in an electric vehicle battery closed loop supply chain," Journal of Cleaner Production, vol. 203, pp. 376-385, 2018.

[15] H. Song and H. Chu, "Incentive strategies of different channels in an electric vehicle battery closed-loop supply chain," Procedia Computer Science, vol. 162, pp. 634-641, 2019.

[16] J. Xie, Y. Li, F. Yang, and L. Liang, "Multilevel contract decision optimization of new energy vehicle closed-loop supply 
chain," Journal of Management Engineering, vol. 34, pp. 180-193, 2020.

[17] J. Acevedo-Chedid, J. Grice-Reyes, H. Ospina-Mateus et al., "Soft-computing approaches for rescheduling problems in a manufacturing industry," RAIRO Operations Research, vol. 55, pp. 2125-2159, 2021.

[18] J. Yu, W. Shi, and Y. Fang, "Construction of low carbon supply chain profit model considering consumer preference," Procedia CIRP, vol. 83, pp. 690-693, 2019.

[19] S. Zhang, C. Wang, C. Yu, and Y. Ren, "Governmental cap regulation and manufacturer's low carbon strategy in a supply chain with different power structures," Computers \& Industrial Engineering, vol. 134, pp. 27-36, 2019.

[20] M. De and B. C. Giri, "Modelling a closed-loop supply chain with a heterogeneous fleet under carbon emission reduction policy," Transportation Research Part E: Logistics and Transportation Review, vol. 133, Article ID 101813, 2020.

[21] V. K. Manupati, S. J. Jedidah, S. Gupta, A. Bhandari, and M. Ramkumar, "Optimization of a multi-echelon sustainable production-distribution supply chain system with lead time consideration under carbon emission policies," Computers \& Industrial Engineering, vol. 135, pp. 1312-1323, 2019.

[22] M. Sykes and J. Axsen, "No free ride to zero-emissions: simulating a region's need to implement its own zeroemissions vehicle (ZEV) mandate to achieve 2050 GHG targets," Energy Policy, vol. 110, pp. 447-460, 2017.

[23] Z. Jing, "Development model of new energy industry in Japan," Japan Forum, vol. 1, pp. 74-79, 2007.

[24] X. Zhu, M. Ren, G. Wu, J. Pei, and P. M. Pardalos, "Promoting new energy vehicles consumption: the effect of implementing carbon regulation on automobile industry in China," Computers \& Industrial Engineering, vol. 135, pp. 211-226, 2019.

[25] J. Xie, L. Liang, L. Liu, and P. Ieromonachou, "Coordination contracts of dual-channel with cooperation advertising in closed-loop supply chains," International Journal of Production Economics, vol. 183, pp. 528-538, 2017.

[26] P. C. Gérard, "Supply chain coordination with contracts," Handbooks in Operations Research and Management Science, vol. 11, pp. 227-339, 2003.

[27] T. Zhao, X. Xu, Y. Chen, L. Liang, Y. Yu, and K. Wang, "Coordination of a fashion supply chain with demand disruptions," Transportation Research Part E: Logistics and Transportation Review, vol. 134, Article ID 101838, 2020.

[28] D. Xiao, J. Wang, and Q. Lu, "Stimulating sustainability investment level of suppliers with strategic commitment to price and cost sharing in supply chain," Journal of Cleaner Production, vol. 252, Article ID 119732, 2020.

[29] T. M. Choi and S. Guo, "Is a 'free lunch' a good lunch? the performance of zero wholesale price-based supply-chain contracts," European Journal of Operational Research, vol. 285, no. 1, pp. 237-246, 2020.

[30] S. M. Hosseini-Motlagh, S. Ebrahimi, and R. Zirakpourdehkordi, "Coordination of dual-function acquisition price and corporate social responsibility in a sustainable closed-loop supply chain," Journal of Cleaner Production, vol. 251, Article ID 119629, 2020.

[31] W. Wu, Q. Zhang, and Z. Liang, "Environmentally responsible closed-loop supply chain models for joint environmental responsibility investment, recycling and pricing decisions," Journal of Cleaner Production, vol. 259, Article ID 120776, 2020.

[32] S. Mitra and S. Webster, "Competition in remanufacturing and the effects of government subsidies," International
Journal of Production Economics, vol. 111, no. 2, pp. 287-298, 2008.

[33] Y. Wang, Z. Yu, M. Jin, and J. Mao, "Decisions and coordination of retailer-led low-carbon supply chain under altruistic preference," European Journal of Operational Research, vol. 293, no. 3, pp. 910-925, 2021.

[34] Z. Tang, C. B. Shi, and Z. Liu, "Sustainable development of tourism industry in China under the low-carbon economy," Energy Procedia, vol. 5, pp. 1303-1307, 2011.

[35] Z. Xie, Y. Zhang, Z. He et al., "Research on patent trend of NEVs industry," China Soft Science, vol. 9, pp. 127-141, 2015.

[36] Y. Zhou, Y. Pu, S. Chen et al., "Government support and development of emerging industries-a new energy industry survey," Economic Research Journal, vol. 6, pp. 147-161, 2015.

[37] X. Bai and H. Meng, "Emerging industries, policy support, and lack of incentives and constraints-taking the new energy automobile industry as an example," Economist, vol. 1, pp. 50-60, 2018.

[38] D. Loorbach, "Transition management for sustainable development: a Prescriptive, complexity-based governance framework," Governance, vol. 23, no. 1, pp. 161-183, 2010.

[39] L. Cheng and L. Qiaochu, "The characteristics of firms' R\&D investment structure and the pattern of economic growthbased on the comparison of firm-level data in China and main countries," Studies in Science of Science, vol. 5, pp. 700-708, 2017.

[40] Y. Wang, R. Fan, L. Shen, and W. Miller, "Recycling decisions of low-carbon e-commerce closed-loop supply chain under government subsidy mechanism and altruistic preference," Journal of Cleaner Production, vol. 259, Article ID 120883, 2020.

[41] F. Olivo, M. C. Junqueira, M. B. Furlan, P. A. Justi, and P. de Morais Lima, "Monetary losses caused by the absence of packaging reverse logistics: environmental and economic impacts," Journal of Material Cycles and Waste Management, vol. 22, no. 6, pp. 1801-1817, 2020.

[42] O. Egbue and S. Long, "Barriers to widespread adoption of electric vehicles: an analysis of consumer attitudes and perceptions," Energy Policy, vol. 48, pp. 717-729, 2012. 